\title{
20. RHODOCHROSITE REPLACEMENT OF INTERNAL MOLDS OF FORAMINIFERS (?)
}

\author{
D. J. Echols, L. Ross, and E. Ringer, Jr., ${ }^{1}$ Washington University, St. Louis, Missouri
}

On Deep Sea Drilling Project Leg 58, the Glomar Challenger drilled five sites in the north Philippine Sea. Three of these sites, 442,443 , and 444 , are in the Shiko$\mathrm{ku}$ Basin. Three holes were drilled at Site 442. Hole 442, a pilot hole to determine wash-in depth for the 16-inch casing, recovered only $15 \mathrm{~cm}$ of sediment. Hole $442 \mathrm{~A}$ penetrated 286 meters of sediment and approximately 30 meters of basalt, and Hole $442 \mathrm{~B}$, a re-entry hole for deep basalt penetration, recovered approximately 22 meters of sediment.

Hole $442 \mathrm{~A}$ was drilled in a water depth of 4639 meters, which is below the present carbonate-compensation depth (CCD). Thirty-one cores were retrieved, containing sediments from late Pleistocene to early Miocene. Foraminifers, although sporadic, were recovered from the Pleistocene and late (?) Pliocene. In all cases, however, they are rare, and preservation is poor, indicating that deposition during this interval was very close to the foraminifer solution depth.

From Core $442 \mathrm{~A}-13$ at 114 meters to Core $442 \mathrm{~A}-21$ at 190 meters the section is barren of foraminifers and nannofossils, suggesting deposition below the CCD.

In Core 442A-21, rare internal molds of what appear to be replaced foraminifers are present. In Core 442A22 they are fairly common, and in Cores $442 \mathrm{~A}-23$ and 442A-24 they are abundant and show more morphological diversity. Under the light microscope, the diversity of forms suggests planktonic foraminifers. Although they are not identifiable to genus in the first series of scanning-electron-microscope photographs prepared, some of the forms show characteristics that we thought diagnostic of benthic foraminifers, especially in what we assumed to be the apertural areas (Plate 1, Figures 1-4). However, we now believe that these "apertural areas" are merely artifacts of preservation and replacement. In the second series of SEM photographs we prepared, the forms seem to resemble planktonic foraminifers (Plate 2, Figures 1-6). Several thin sections were ground, and in a few it is possible to detect chamber arrangements also suggestive of planktonic forms.

Surface features revealed in the SEM photographs show that replacement has occurred in rhombic crystals (Plates 1-3). Figure 1 of Plate 3 shows a fragmented diatom on the surface of a foraminifer (?), and Figures 2 and 3 of Plate 3 show a coccolith, with some overgrowth, nestled in the diatom.

\footnotetext{
${ }^{1}$ Present address: Shell Oil Company, New Orleans.
}

X-ray-diffraction patterns identify the replacement mineral as rhodochrosite. Comparison of data on the replaced molds and rhodochrosite standard is given in Table 1.

Atomic-absorption spectroscopy showed 7 per cent calcium (carbonate) and 3 per cent magnesium (carbonate); colorimetry showed 90 per cent manganese (carbonate).

If indeed these replacements represent calcareous foraminifers, their preservation in an otherwise barren section is puzzling. Although it cannot be ruled out, there is no evidence that these forms were transported or reworked. Their presence seems to imply that during the time span represented by the enclosing sediments deposition may have been somewhat above the CCD. It is interesting to note that when the foraminifer solution index is plotted for the sites in the Shikoku Basin, the zone in which these forms are found correlates with times of advanced solution at Sites 443 and 444 (Figure 1).

It is impossible to say whether the identical situation exists in Hole 442B for this hole was washed down to 267.5 meters, and the first core was recovered at this depth. In Core 442B-1, rare replaced forms are present, and the core seems to be equivalent to Core $442 \mathrm{~A}-27$ or 442A-28. It is not now possible to explain satisfactorily the occurrence of these replaced forms, but it should be noted that this may be a very local phenomenon, for they were not detected in any of the other foraminifer samples studied for other sites drilled on Leg 58 .

TABLE 1

Comparative X-Ray-Diffraction Data

\begin{tabular}{cccr}
\hline \multicolumn{2}{c}{$\begin{array}{c}\text { Replaced Internal Molds } \\
d\end{array}$} & $I$ & \multicolumn{2}{c}{$\begin{array}{c}\text { Rhodochrosite Stan- } \\
\text { dard (ASTM) }\end{array}$} \\
\hline 3.675 & 40 & 3.66 & $I$ \\
2.856 & 100 & 2.84 & 35 \\
2.398 & 25 & 2.39 & 100 \\
2.188 & 30 & 2.172 & 20 \\
2.010 & 25 & 2.000 & 27 \\
- & too faint to read & 1.829 & 23 \\
1.783 & $<35$ double & 1.770 & 12 \\
& & 1.763 & 30 \\
1.545 & 10 & 1.533 & 33 \\
1.463 & 5 & 1.452 & 12 \\
1.392 & 7 & 1.379 & 1 \\
- & too faint to read & 1.221 & 10 \\
\end{tabular}


The general appearance of the assemblage, its abundance, and the lack of evidence of transport lead us to believe that we are dealing with a replaced planktonic fauna. Therefore, at this stage we conclude that this assemblage locally escaped obliteration by rapid burial and rapid replacement.

\section{ACKNOWLEDGMENTS}

We wish to acknowledge the assistance of Dr. L. Haskin and B. Curtis for the atomic-absorption and colorimetry analysis; Dr. K. Goettel and D. Kremser for X-ray diffraction results; and D. Tasker for assistance with the SEM photography.

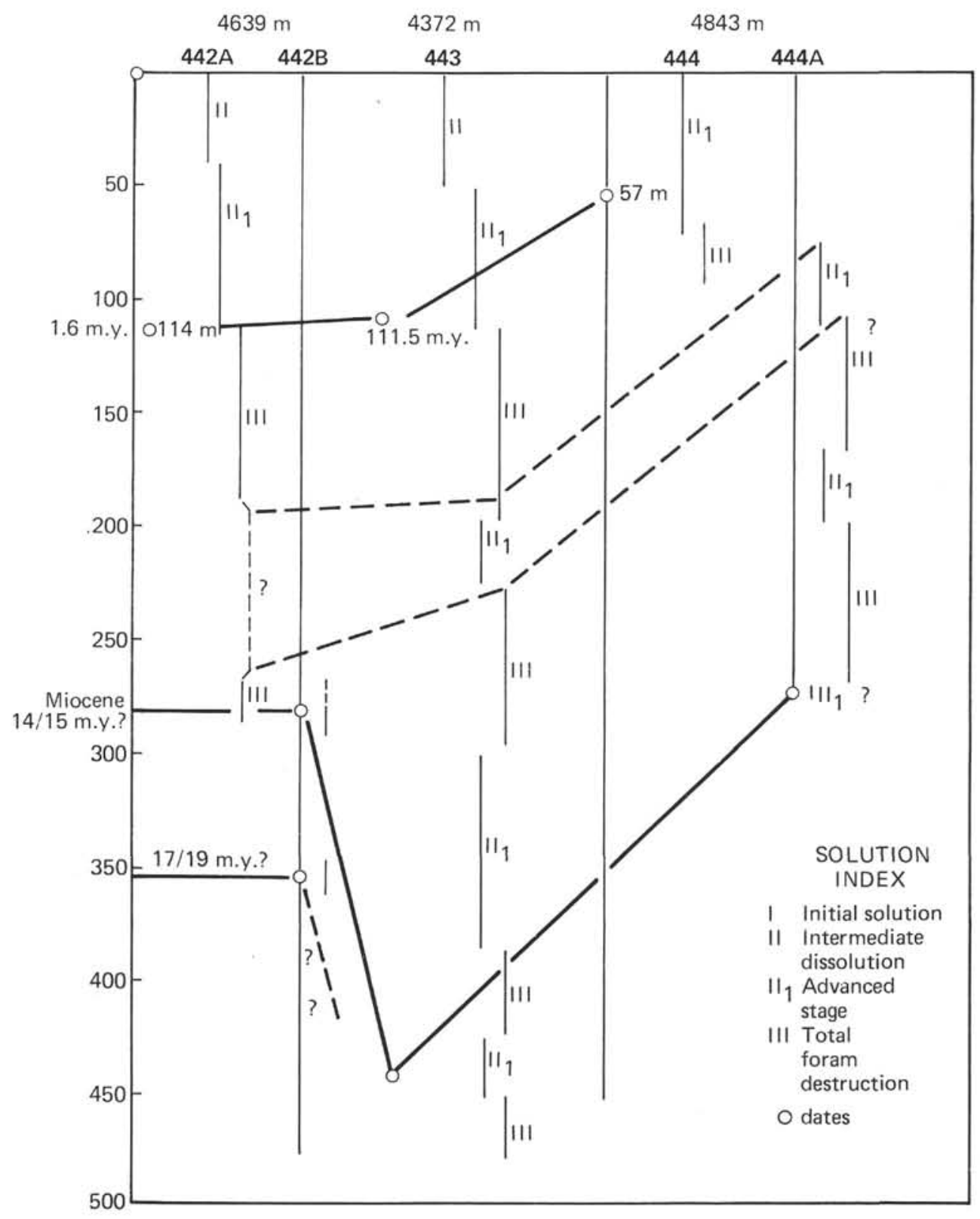

Figure 1. Correlation of solution indexes at Sites 442, 443, and 444, based on the foraminifers. Dashed line in Hole $442 \mathrm{~A}$ defines interval in which replaced foraminifers were encountered. 
PLATE 1
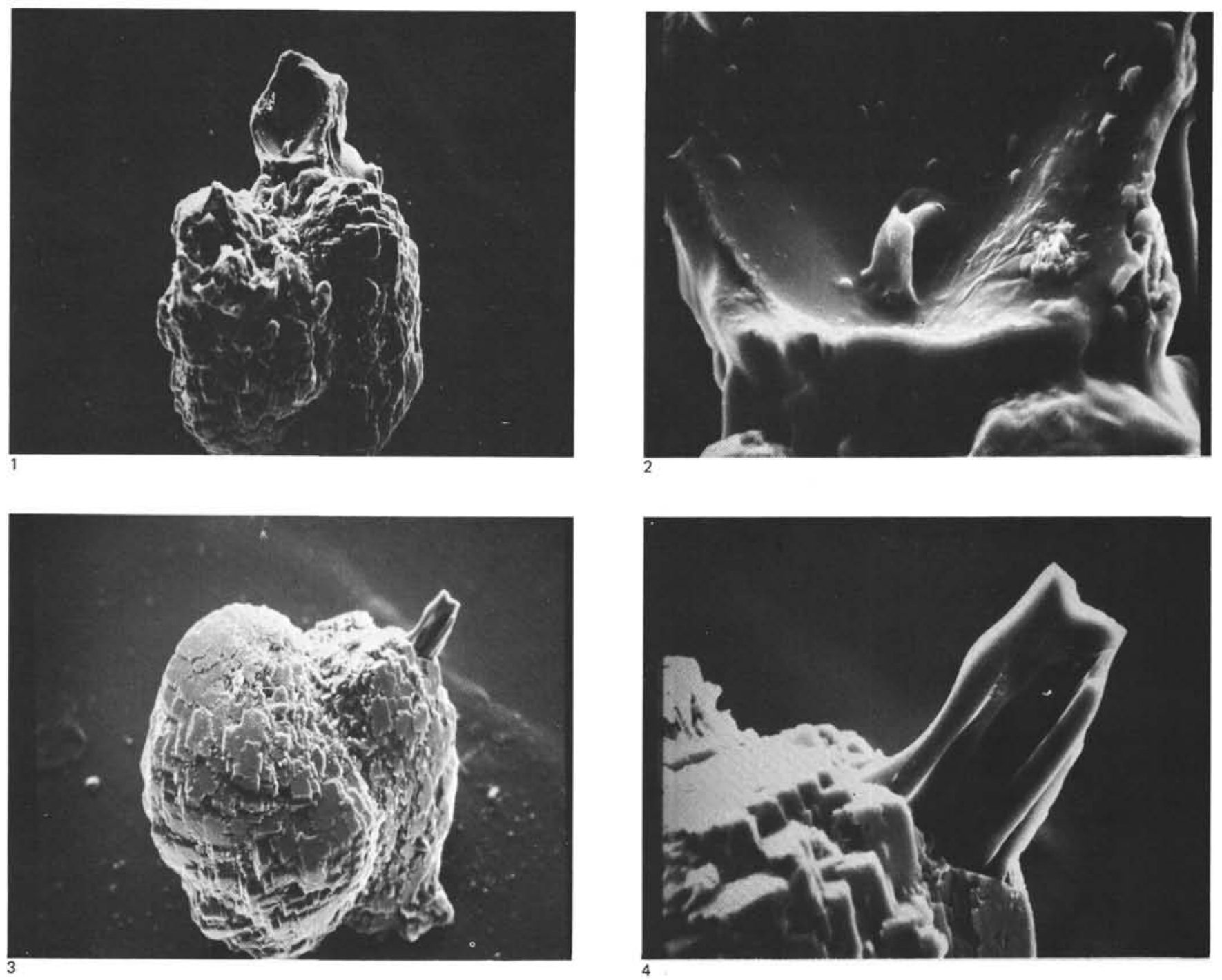

Figure 1

Replaced foraminifer, $\times 210$.

Figure 2

Detail of specimen in Figure 1, $\times 1400$.

Figure $3 \quad$ Replaced foraminifer, $\times 270$.

Figure 4 Detail of projection on specimen in Figure 3, $\times 12,100$. 

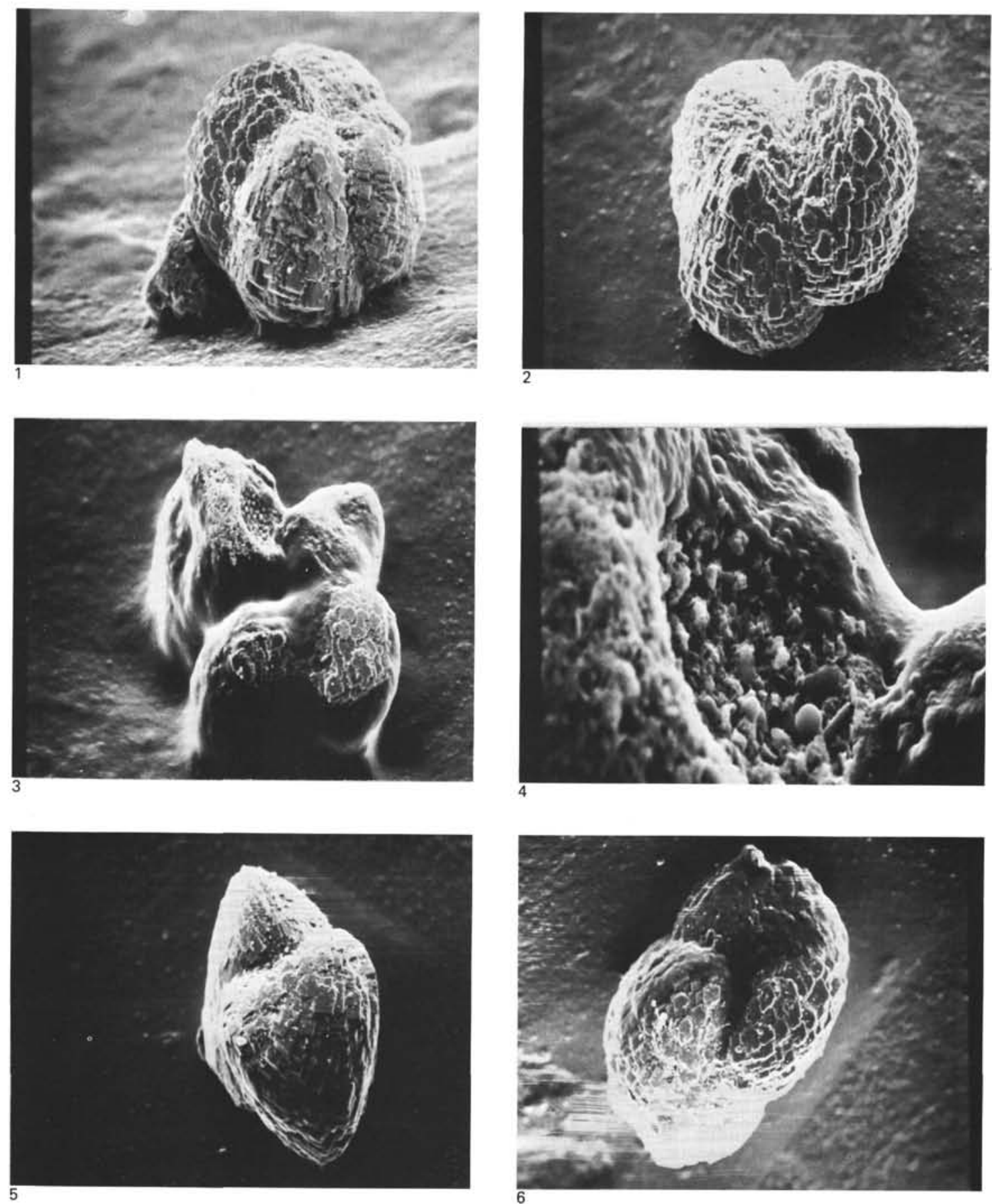

All photographs clearly illustrate rhombic crystallization.

Figures 1, 2

Figure 3

Figure 4

Figures 5, 6
Replaced coiled planktonic (?) foraminifers.

Figure $1, \times 225$. Figure $2, \times 232.5$.

Replaced planktonic foraminifer, $\times 182$.

Detail of specimen in Figure 3, $\times 980$.

Replaced foraminifers. Figure 5, $\times 160$. Figure $6, \times 170$. 


\section{PLATE 3}
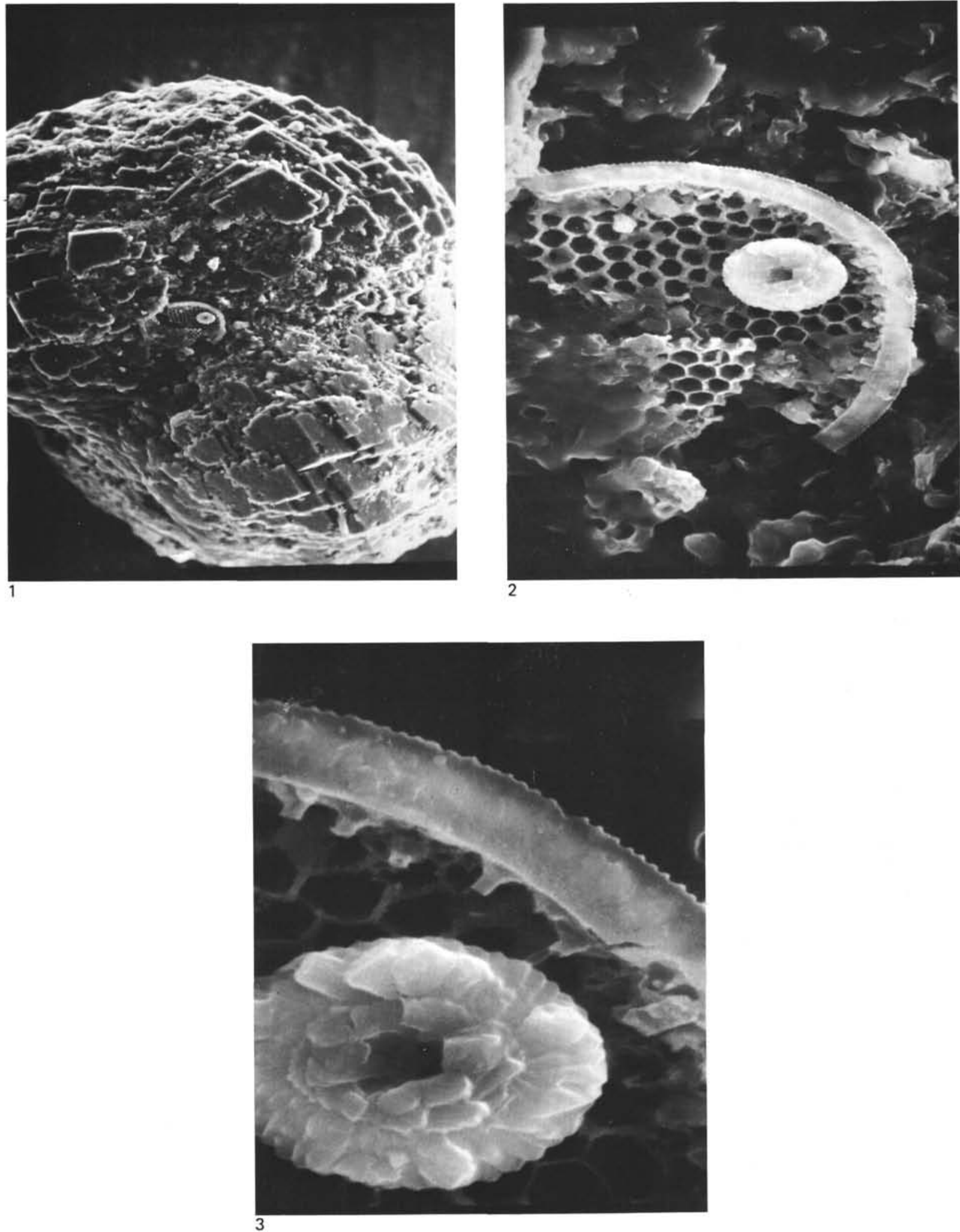

Figure 1

Replaced foraminifer showing rhombic crystals, fragmented diatom, and coccolith, $\times 390$.

Figures 2, 3 Close-up of diatom and coccolith of Figure 1. Figure 2, $\times 2,500$. Figure $3, \times 7,500$. 